\title{
DESIGN AND SIMULATION OF MARINE AND TIDAL CURRENT CONVERTERS USING DC-DC BOOST CONVERTER
}

\author{
Abou-Hashema M. El-Sayed, Emad El-Bakoury \\ Interdisciplinary graduate school of Engineering Sciences, Kyushu \\ University, Japan abouhashema@gmail.com
}

(Received July 6, 2009 Accepted August 5, 2009).

\begin{abstract}
Due to highly demand on the renewable energy sources as a free and a clean power resource, extracting energy from unsteady flow using marine and tidal current turbines has a special focusing nowadays. For their resource characteristic, extracting energy from them needs more simple and robust converter in order to avoid the drawbacks of the mechanical system such as gearbox and makes the marine/tidal current energy more reliable. The required $A C-D C$-AC conversion system equipped with $D C$ $D C$ boost converter has been designed. To investigate the efficient performance of that conversion system especially at low current speed, different operating conditions were studied; the system was tested with/without boost converter at different current speeds operation. Moreover, the effect of including boost converter on the total harmonic distortion THD is checked.
\end{abstract}

\section{INTRODUCTION}

Free flow marine currents i.e. unregulated water courses, tides, and other ocean currents, are energy resources yet to be utilized in the commercial scale. This non fossil source can give an environmentally great contribution to the world electricity production [1].

A number of projects around the world involved in extracting energy from these resources exist and most concepts are similar to wind energy converters in that they include a turbine, generator, and a power electronic interface to feed an isolated load or integrated with the grid $[2,3]$.

Wind power is similar to marine/tidal current energy as they considered with harnessing the kinetic energy in a flowing fluid. However, there are also a number of significant differences, such as in the wind energy the difference between cut in and the cut off speed reaches about 10-15 m/s so a maximum power point tracker (MPPT) and hence a gear box are needed to pick the maximum power of the intercepted wave. In the other way, the marine current converter faces more difficult problem that most parts of the system will be submerged in the water and thus not easily accessible, so it is good to avoid mechanical complex systems (such as gearboxes) by using generators suitable for variable speed and load operation [1].

Although the use of the induction generators (IG) are a commonly choice used in the field of renewable energy especially in the wind energy [4], but the main drawback of these generators is their operation at higher speed and not available at lower speed as in the case of marine /tidal current converters. Consequently, it needs a gearbox to accelerate the induction generators. 
Moreover, it is concluded in [5] that up to $20 \%$ of the downtime for a wind power plant is due to gearbox failures, and that the majority of these failures are due to wears. Therefore, avoiding gearboxes, yawing and blade pitching are likely to be beneficial for system reliability, but require certain adaptation for the rest of the system.

So the other substitution of the induction generators in marine and tidal energy converters is synchronous generator (SG). Synchronous machines tend to have a large number of poles especially in the salient pole type i.e. it is available at low speeds about $10 \mathrm{rpm}[1]$.

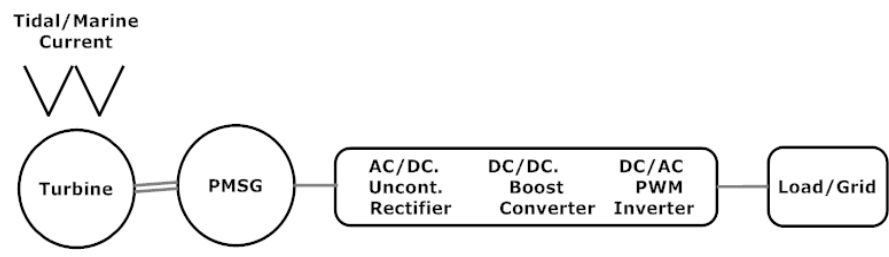

Fig. 1 Schematic diagram for marine/tidal current

Marine/tidal current turbine generator usually supplies an $A C$ voltage lower than the grid voltage and frequency, and their output voltage varies in a wide range according to various operation conditions. Some boosting techniques are needed to boost the output $D C$ voltage supplied by the rectifier system then invert it into an $A C$ voltage with the desired voltage and frequency $[6,7]$.

In this paper enhancing the performance of $A C-D C-A C$ conversion system by including a boost $D C-D C$ converter has been studied. Also, the performance of such conversion system is checked at different current speeds and loading conditions using MATLAB simulation with Sim Power Systems toolbox.

\section{II.SYSTEM DESCRIPTION}

\section{A- Power Generation System}

The studied system is composed of a marine current turbine, a PMSG, and a back-toback three phase converter contains a DC-DC boost converter as shown in Fig. 1. this system can feed either an isolated load or a strong electrical grid. However, in this paper special concentration to feed an isolated load with regulated voltage and frequency is done. This is the status for the off shore marine/tidal current turbines or when there is no availability to connect to the grid. All the marine current converter stages were implemented on the Matlab SimPowerSystems toolbox to check the system response when there are some undesirable conditions such as increasing or decreasing of the marine/ tidal current speeds.

\section{B- Turbine model}

For the marine and tidal current turbine modeling, the expression of the extractible power $P_{t}$, as a function of the water flow speed and turbine parameters is

$$
P_{t}=\frac{1}{2} \rho C_{p} S w^{3}
$$


Where $\rho$ is the water density, $C_{p}$ is the non-dimensional power coefficient (expressing the turbine efficiency), $S$ is the surface swept area by the turbine blades, and $w$ is the water flow speed. The surface area $S$ is defined as

$$
S=2 R_{T} H_{T}
$$

Where $R_{T}$ is the turbine radius and $H_{T}$ is the turbine height [8]. To simulate the variation of the marine/tidal current speed, a complete model for the turbine is not included, but it is simulated as prim mover with different speeds.

\section{III.CONTROL STRATEGY}

In order to control the frequency and the load voltage as the current speed changes the architecture of the designed control system is shown in Fig. 2. The control strategy can be separated into two main operations.

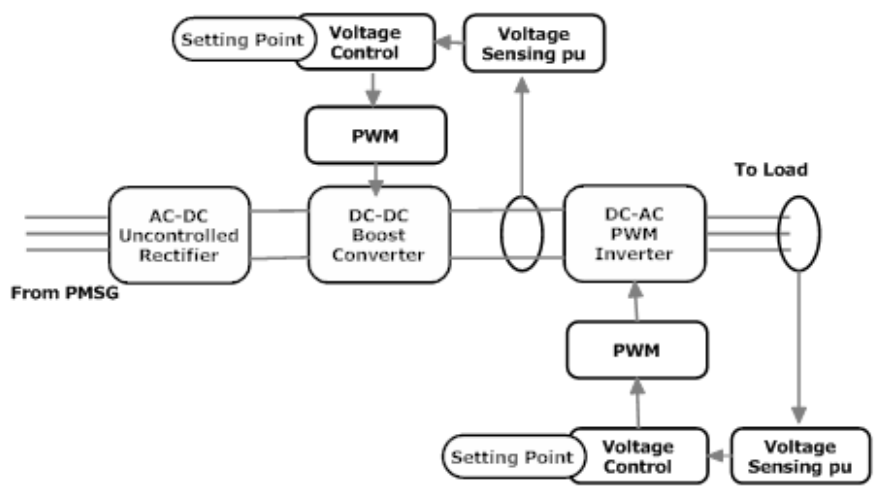

Fig. 2 Architecture of the AC-DC-AC conversion system

\section{A-Controlled rectifier}

This rectifier containing uncontrolled bridge rectifier is followed by a boost DC-DC converter. The steady state input/output relationship for the boost converter in the continuous conduction mode (CCM) is

$$
\frac{V_{d c}}{V_{\text {in }}}=\frac{1}{1-D} \quad 0<D<1
$$

Where $D$ is the converter duty cycle. $V_{i n}$ is the rectified DC voltage, and $V_{d c}$ is the inverter input dc voltage. The role of the Boost DC-DC converter is in charge to regulate and maintain the inverter DC input voltage to a suitable value that allows the inverter to transform this DC voltage to the desired load voltage (Vrms) and the frequency, that can be done by controlling the boost converter duty cycle using a feedback control loop occupied with a PI controller that will drive the PWM driver, as shown in Fig. 3.

To avoid the mal operation of the PWM inverter, the discontinuous conduction mode (DCM) of the boost converter should be avoided. This can be done by designing the elements of the DC filter (composed of L and C) as in (4), and (5) [9]. 


$$
\begin{aligned}
& L \geq L_{b}=\frac{(1-D)^{2} D R}{2 f} \\
& C \geq C_{\min }=\frac{D V_{d c}}{V_{r} R f}
\end{aligned}
$$

Where $f$ is the switching frequency, $V_{\mathrm{dc}}$ is inverter input dc voltage, $V_{r}$ is the voltage ripple in the inverter input voltage, and $R$ is the equivalent load resistance seen by the boost converter that can be computed from (6),

$$
V_{d c} I_{d c}=V_{d c}^{2} / R=\operatorname{Re}\left(\sqrt{3} V_{a c} I_{a c}{ }^{*}\right)
$$

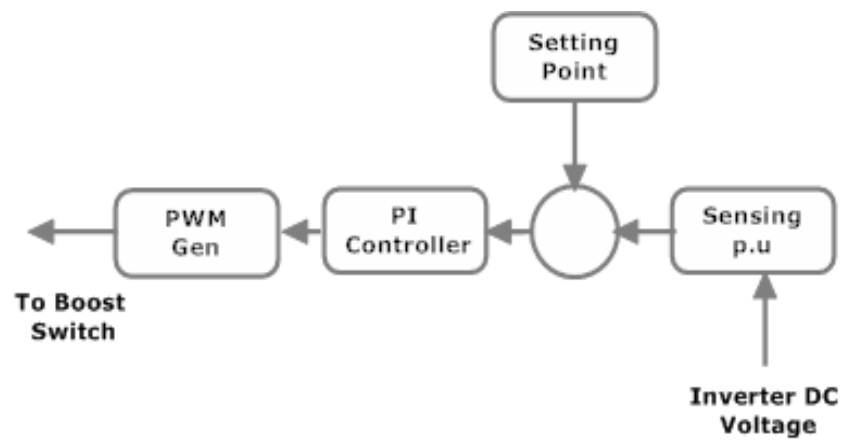

Fig. 3 Schematic diagram of voltage control of the boost converter

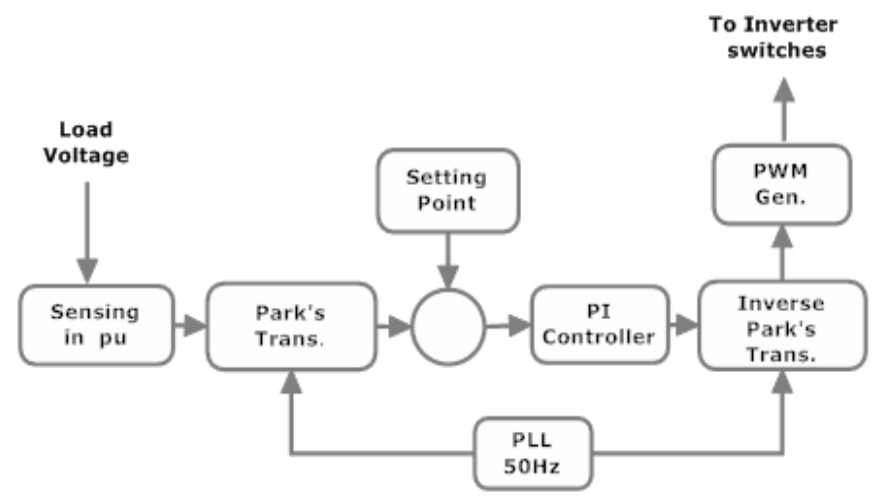

Fig. 4 Schematic diagram of the voltage control system for PWM inverter

\section{B- Load side converter}

This converter is in charge to control the voltage and the frequency at the load; these can be done using PWM driver. The different stages of the voltage control are implemented in Fig. 4. After transforming the three phases load voltage into $d q 0$ reference frames with the help of the phase lock loop $(P L L)$ at $50 \mathrm{~Hz}$, these components are compared with the setting points, then the PI controller will generate the direct axis modulation index, and the quadrature axis modulation index $\left(m_{d}, m_{q}\right)$. To avoid the saturation of the inverter (square wave mode), the modulation indices should satisfy (7). The root mean square of the load voltage can be computed from (8) 


$$
\begin{aligned}
& m_{a}=\sqrt{m_{d}{ }^{2}+m_{q}{ }^{2}} \leq 1 \\
& V_{r m s}=\frac{\sqrt{3}}{2 \sqrt{2}} m_{a} V_{d c}
\end{aligned}
$$

Where $m_{a}$ is the amplitude modulation index, $V_{d c}$ inverter dc input voltage, and $V_{r m s}$ is the load root mean square line voltage.

\section{SIMULATION RESULTS}

In order to test the performance of the conversion system including the boost converter, a numerical simulation in MATLAB/SimPowerSystems environment have been done. The variation of the current speed is simulated as a step change in the generator revolution per minute (rpm).

Because the marine/tidal current has low current speed $(0-2 \mathrm{~m} / \mathrm{s})$ with respect to wind energy, the performance of the conversion system has been tested at low revolution speed (25 rpm).

Figure 5 shows the performance of the AC-DC-AC conversion system with and without boost converter. It has been noticed that the conversion system with boost converter can regulate the voltage over the load. Moreover, the conversion system without boost converter can't regulate the voltage over that load which is due to the lower value of the inverter input dc voltage $(110 \mathrm{~V})$. By using (8) the maximum ac line voltage is about $67 \mathrm{~V}$. Also, introducing the boost converter to the conversion system decreases the amount of the harmonic distortion (THD) by $45 \%$.

Figure 6 shows that, as the generator speed increases by $20 \%$ the generator induced voltage, and the rectified DC voltage increase. The role of the boost converter is successfully managed to maintain a suitable voltage that can enable the PWM inverter to generate the setting load voltage. Moreover, without the boost converter the rotation speed is too low to generate a DC voltage allowing the PWM inverter to regulate the load voltage.

Figure 7 shows that, with the generator speed is doubled, the performance of the conversion system without boost converter improved. Now the generated DC voltage is sufficient to handle the PWM inverter to regulate the load voltage. Similarly, the performance of the conversion system with boost converter can regulate the load voltage without any problems for higher speed.

To simulate a more practical marine/tidal current case, the generator speed has been allowed to change by $20 \%$ from the unit speed $(25 \mathrm{rpm})$ every $0.5 \mathrm{sec}$. (15 cycles) and the performance is checked.

Figure 8 shows that, as the current speed (generator speed) changes, the performance of the conversion system with the boost converter is better than that without the boost converter. With the boost converter the conversion system managed to regulate the load voltage without any regulation error.

The effect of including the boost converter on the amount of the harmonic content has been tested. Fig. 9 shows that including boost converter. At low speed, the boost converter reduces THD by $45 \%$ from its ratio without boost converter. Also, THD is reduced by increasing the current speed (increasing generator speed), which is due to the increased rectified DC voltage. 


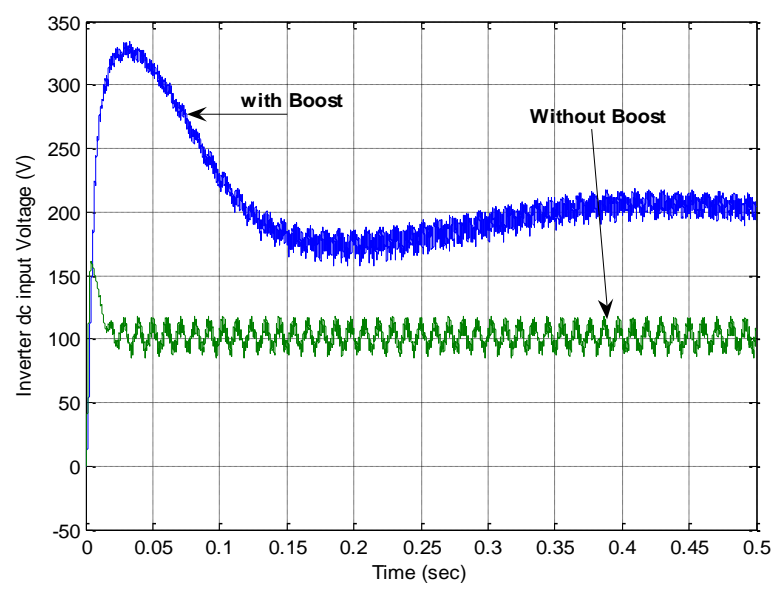

(a) Inverter dc input voltage

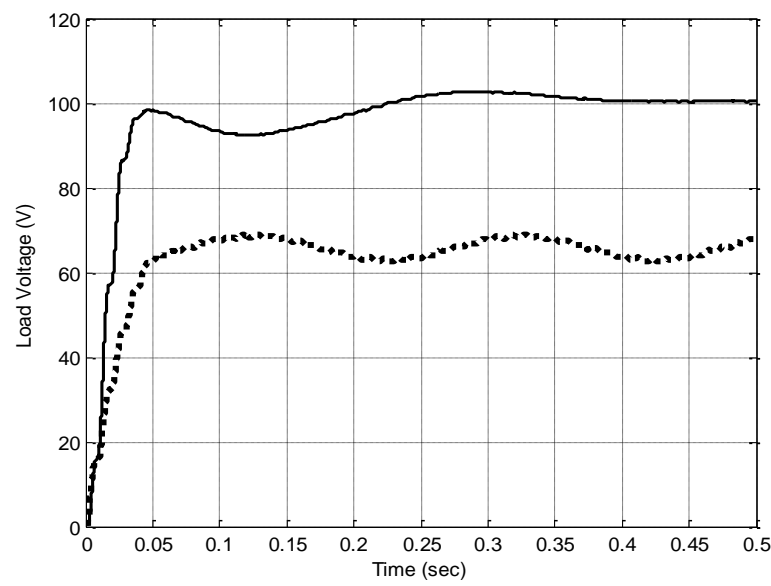

(b) Load voltage (volt)

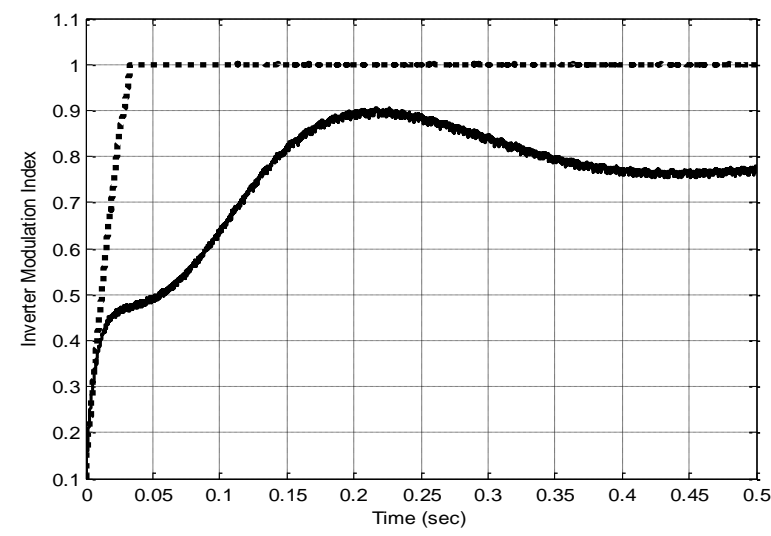

(c) Inverter modulation index

Fig. 5 Dynamic response at generator speed $25 \mathrm{rpm}$ 


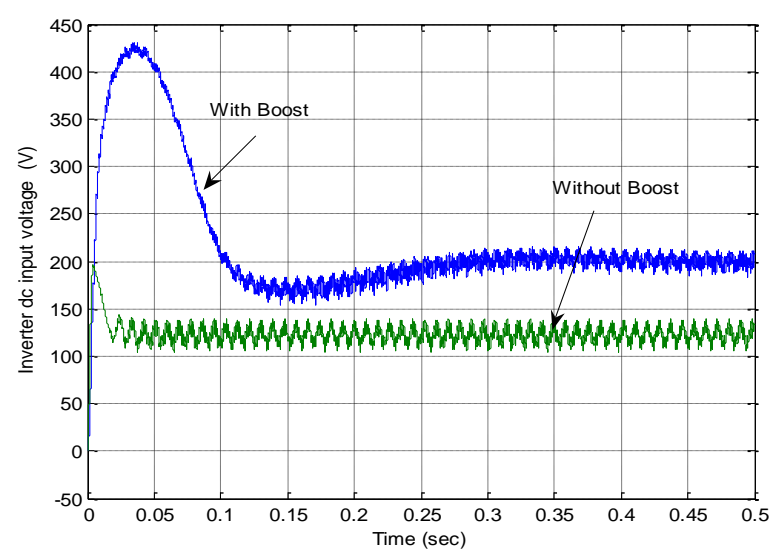

(a) Inverter dc input voltage

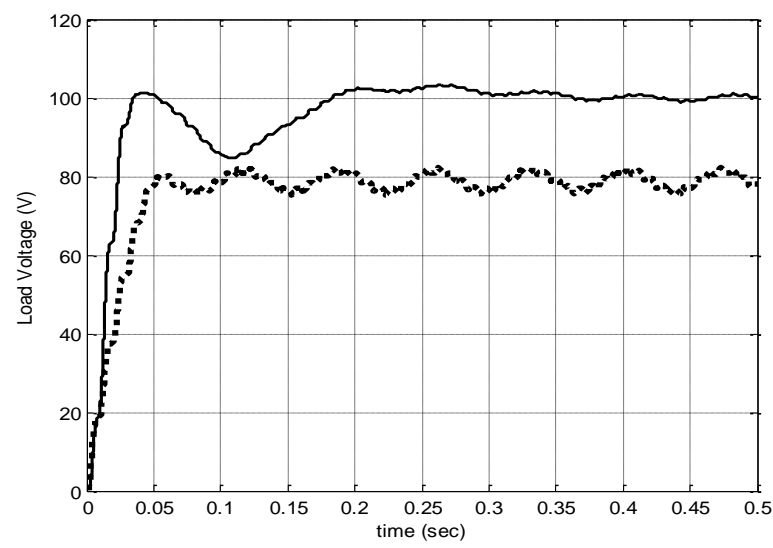

(b) Load voltage (volt)

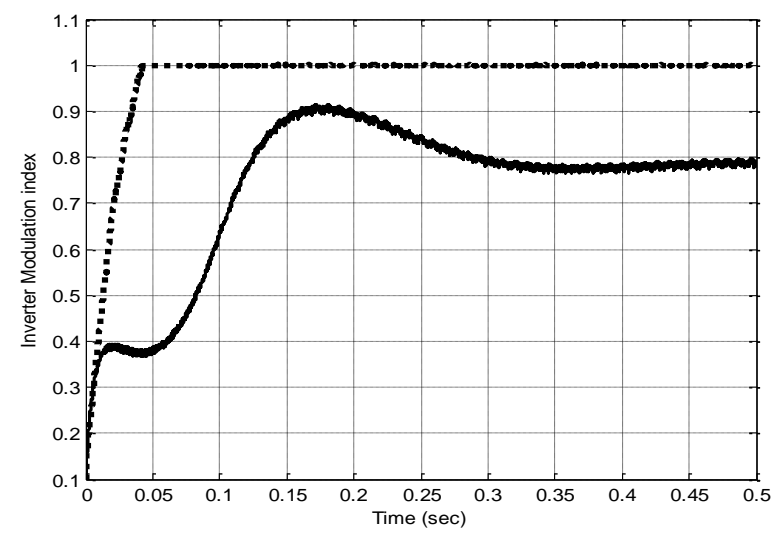

(c) Inverter modulation index

Fig. 6 Dynamic response at generator speed increased by $20 \%$ from the unit speed (25 rpm) 


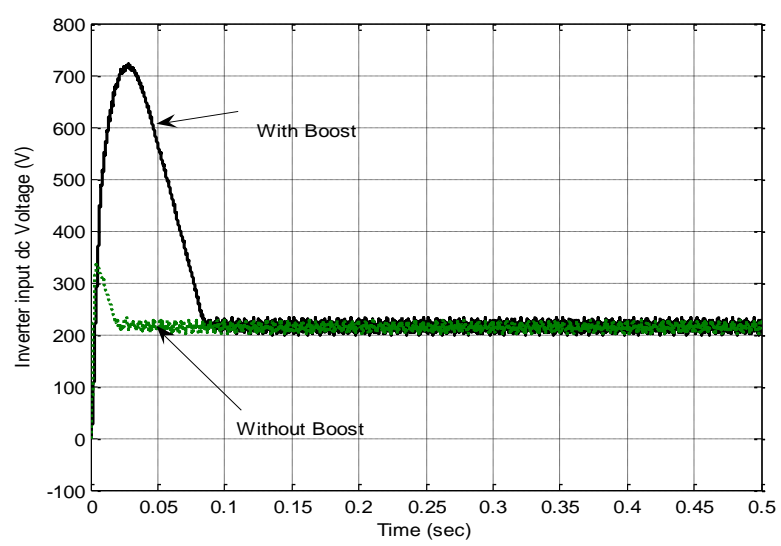

(a) Inverter dc input voltage

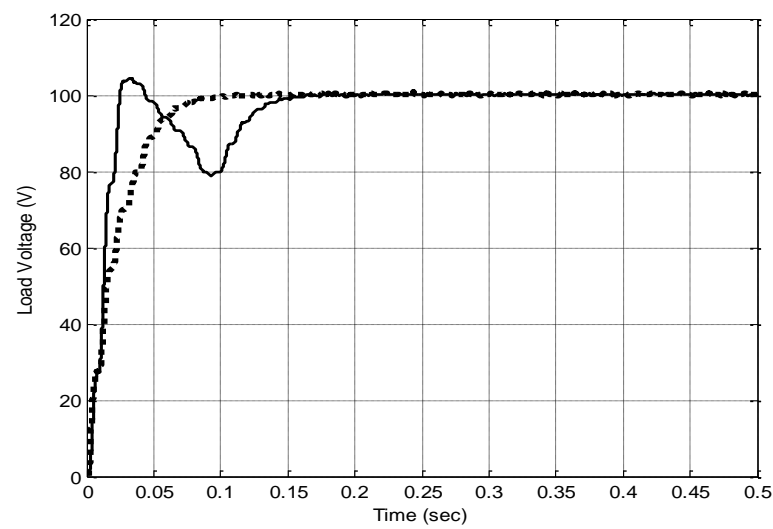

(b) Load voltage (volt)

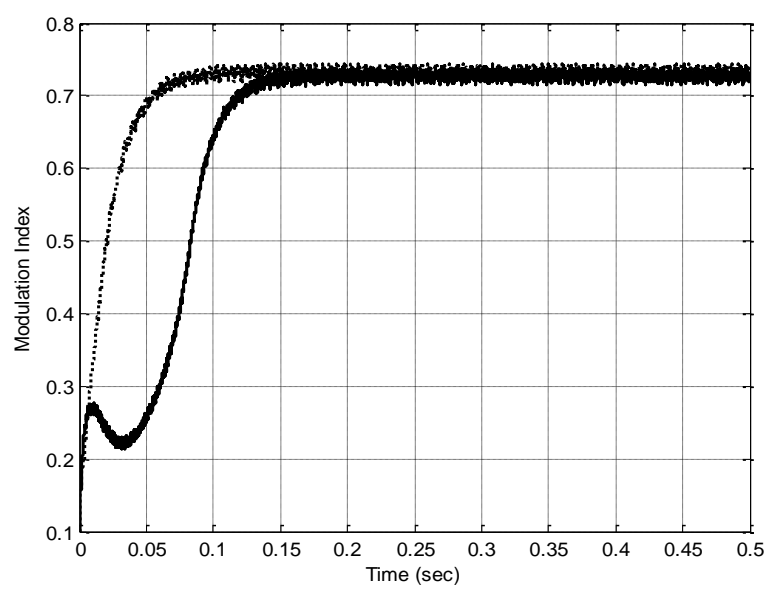

(c) Inverter modulation index

Fig. 7 Dynamic response at double generator speed (50 rpm) 


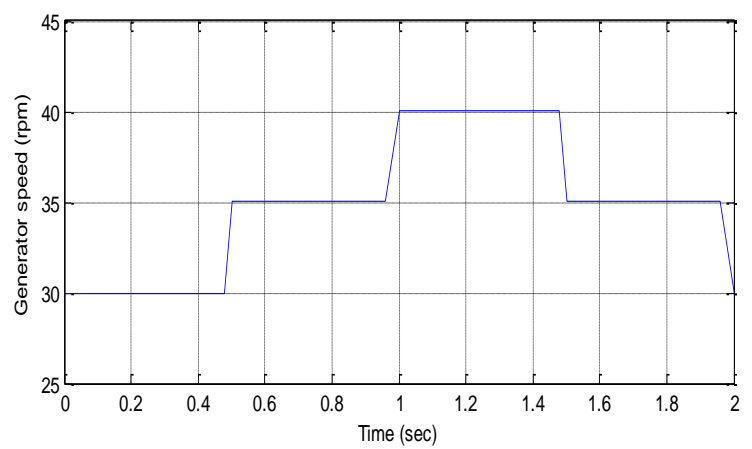

(a) Generator speed (rpm)

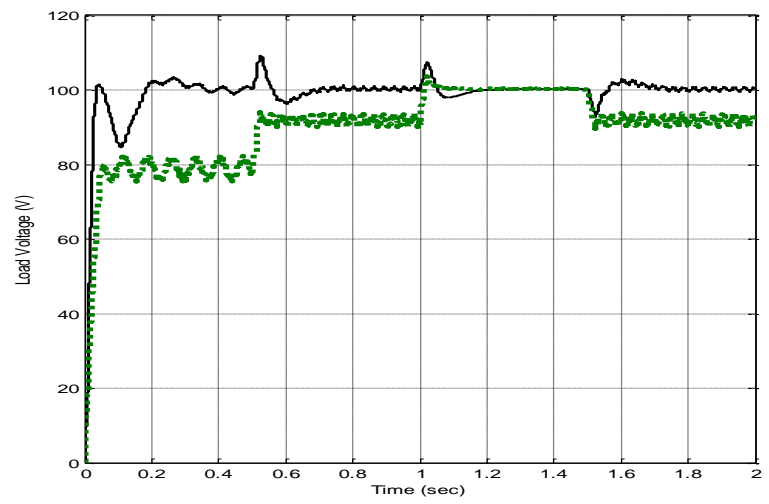

(b) Load voltage (volt)

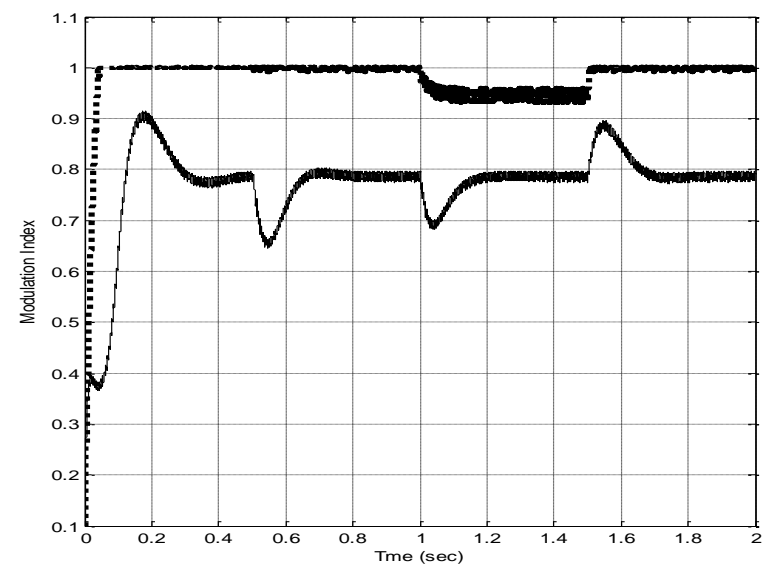

(c) Inverter modulation index

Fig. 8 Dynamic response with different generator speeds (rpm) 


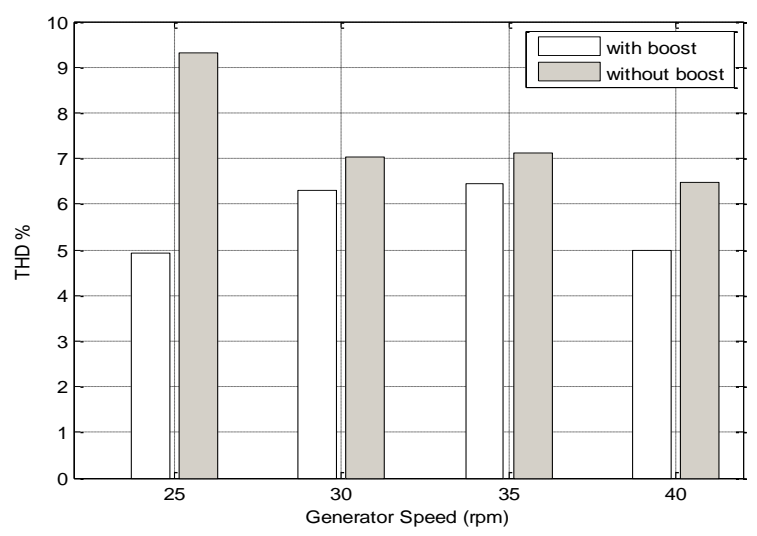

Fig. 9 Total harmonic distortion (THD)

\section{V.CONCLUSION}

A marine and tidal current energy conversion system has been considered in this paper, and the present article is oriented on presenting the importance of including a DC-DC boost converter to the AC-DC-AC conversion system.

The Boost DC-DC converter plays an important role in regulating the voltage over the isolated load especially at low generator speed (low current speed). Without the boost converter the voltage can't be regulated due to the lower value of the inverter DC input voltage. Moreover, including the DC-DC boost converter in the conversion system enables the PWM inverter operation in the linear mode of the modulation index without entering saturation mode $\left(m_{a} \geq 1\right)$. The total harmonic distortion decreased as a result.

Regarding to grid integration of the marine/tidal current energy, it is concluded from the simulation results that the AC-DC-AC conversion system with the boost type converter has the ability to be connected with the grid due to the regulated voltage and frequency.

Also, including a boost type converter to the conversion system will allow harnessing the marine/tidal current energy in lower as well as higher current speed without any problem. In other words, the cut in speed $\left(C_{i n}\right)$ for generating the electrical power will be lower than the conversion system without boost converter i.e. this will increase efficiency and reliability of the conversion system.

Including a DC-DC boost converter is mandatory in low speed operation, as in the case of marine/tidal current, especially, when it is unavailable to use gearboxes

\section{REFERENCES}

[1] K. Yuen, K. Thomas, M. Grabbe, et al," Matching a Permanent Magnet Synchronous Generator to a Fixed Pitch Vertical Axis Turbine for Marine Current Energy Conversion”, IEEE J. Ocean Eng., Vol. 34, No.1, Jan. 2009.

[2] IT Power, Seacore, G. Kassel and J. Kestererman, "Sea flow-World's first pilot project for the exploitation of marine currents at a commercial scale", EUR 21616, 2005, pp. 1-34, ISBN: 92-894-4593-9. 
[3] S. E. Ben Elghali, R. Balme, K. Le Saux, et al, "A simulation model for the evaluation of the electrical power potential harnessed by a marine current turbine", IEEE J. Ocean Eng., Vol. 32, No. 4, pp. 786-789, Oct. 2007.

[4] J. M. Carrasco, L. G. Franquelo, et al, "Power Electronic Systems for the grid Integration of Renewable Energy Sources; A Survey", IEEE, Industrial Electronic Trans., Vol. 53, No. 4, Aug. 2006.

[5] J. Ribrant, L. Bertling, et al, " Survey of Failures in Wind Power Systems with Focus on Swedish Wind Power Plants during 1997-2005", IEEE, Energy Conversion Trans., Vol. 22, No. 1, pp. 167-173, Mar. 2007.

[6] Y. Chen, K. Smedley, "A cost effective single stage inverter with maximum power point tracker", IEEE trans., Power Electronic, Vol. 19, No. 5, pp. 1289-1294, Sep. 2004.

[7] Yang Chen, K. Smedley, "Three- Phase Boost-Type Grid Connected Inverter", IEEE trans., Power Electronics, Vol. 23, No. 5, pp. 2301-2309, Sep 2008.

[8] A. Andeica, S. Bacha, "Micro-Hydro Water Current Turbine Control for Grid Connected or Islanding Operations", IEEE, 978-1-4244-1668-4, 2008.

[9] M. H. Rashid, "Power Electronic Hand Book", Academic press, Canda, 2001

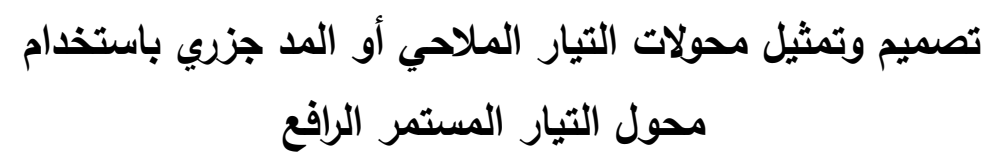

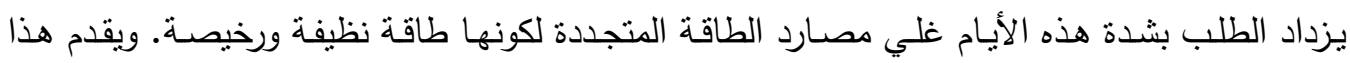
البحث طريقة جديدة لاستغلال طاقة المد والجزر والأمواج في توليد الطاقة الكهربية.

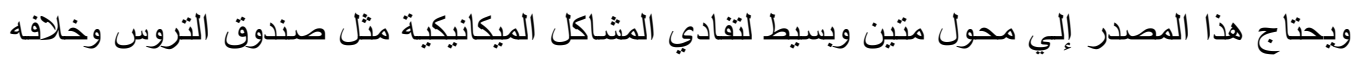

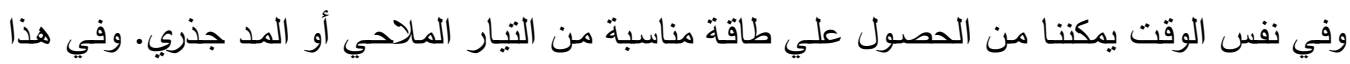

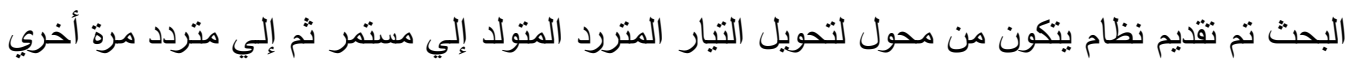

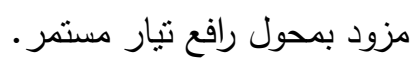

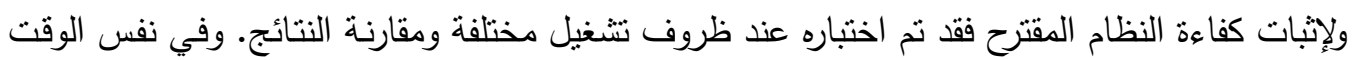
نم دراسة تأثير استخدام محول التيار المستمر علي معامل التشوه الكلي. 